\title{
Complications to 6 months following total hip or knee arthroplasty: observations from an Australian clinical outcomes registry
}

\author{
Sung Mu Heo ${ }^{* *}$, lan Harris², Justine Naylor² and Adriane M. Lewin²
}

\begin{abstract}
Background: Total hip and total knee arthroplasty (THA/TKA) are increasing in incidence annually. While these procedures are effective in improving pain and function, there is a risk of complications.

Methods: Using data from an arthroplasty registry, we described complication rates including reasons for reoperation and readmission from the acute period to six months following THA and TKA in an Australian context. Data collection at 6 months was conducted via telephone interview, and included patient-reported complications such as joint stiffness, swelling and paraesthesia. We used logistic regression to identify risk factors for complications.

Results: In the 8444 procedures included for analysis, major complications were reported by 9.5 and $14.4 \%$ of THA and TKA patients, respectively, whilst minor complications were reported by 34.0 and $46.6 \%$ of THA and TKA patients, respectively. Overall complications rates were 39.7 and 53.6\% for THA and TKA patients, respectively. In THA patients, factors associated with increased risk for complications included increased BMI, previous THA and bilateral surgery, whereas in TKA patient factors were heart disease, neurological disease, and pre-operative back pain and arthritis in a separate joint. Female gender and previous TKA were identified as protective factors for minor complications in TKA patients.

Conclusion: We found moderate rates of major and high rates of minor postoperative complications following THA and TKA in Australia and have identified several patient factors associated with these complications. Efforts should be focused on identifying patients with higher risk and optimising pre- and post-operative care to reduce the rates of these complications.
\end{abstract}

Keywords: Total hip arthroplasty, Total knee arthroplasty, Primary joint replacement, Registry, Epidemiology, Complication, Readmission, Reoperation, Infection

\footnotetext{
* Correspondence: brian.sm.heo@gmail.com

${ }^{1}$ Hornsby-Kuringai Hospital, Palmerston Road, Hornsby, Sydney, NSW 2077, Australia

Full list of author information is available at the end of the article
}

(c) The Author(s). 2020 Open Access This article is licensed under a Creative Commons Attribution 4.0 International License, which permits use, sharing, adaptation, distribution and reproduction in any medium or format, as long as you give appropriate credit to the original author(s) and the source, provide a link to the Creative Commons licence, and indicate if changes were made. The images or other third party material in this article are included in the article's Creative Commons licence, unless indicated otherwise in a credit line to the material. If material is not included in the article's Creative Commons licence and your intended use is not permitted by statutory regulation or exceeds the permitted use, you will need to obtain permission directly from the copyright holder. To view a copy of this licence, visit http://creativecommons.org/licenses/by/4.0/ The Creative Commons Public Domain Dedication waiver (http://creativecommons.org/publicdomain/zero/1.0/) applies to the data made available in this article, unless otherwise stated in a credit line to the data. 


\section{Background}

Total hip and total knee arthroplasty (THA, TKA) are effective interventions for osteoarthritis and are increasing in incidence annually. The Australian National Joint Replacement Registry reported 49,764 THA and 65,266 TKA procedures in 2018 [1]. Over 90,000 THA and over 1.1 million TKA procedures were undertaken in 2018 in the UK, whilst in the US, incidence is estimated to grow to 572,000 THA and 3.48 million TKA procedures per annum by 2030 [2]. While these procedures are effective in improving pain and function [3-7], there is a risk of complications. The most common complications requiring readmission for hip arthroplasty are dislocation and infection, whereas infection dominates following knee arthroplasty $[8,9]$. Measuring and understanding rates of these events comprise important components of both informed consent and shared decision-making.

Complication rates following THA and TKA are reported using a broad range of metrics and time points. Reported complication rates vary widely, partly based on inclusion criteria (e.g. 'major' versus 'minor' complications), reporting base (e.g. single-centre cohorts versus nationwide registries), and length of follow up [10-14]. For example, 90-day venous thromboembolism rates reported in a nationwide database analysis in South Korea were $3.9 \%$ for THA and $3.8 \%$ for TKA, whereas inhospital symptomatic DVT rates as reported in a systematic review were 0.26 and $0.63 \%$ for THA and TKA respectively, and PE rates at $0.14 \%$ and $0.27 \%$ for THA and TKA respectively $[15,16]$. Further, readmission rates following THA and TKA range from $0.27 \%$ from a single centre at 30 days post-operatively to 10.5 and $8.6 \%$ at 90 days for THA and TKA respectively in large analyses using US Medicare national hospital claims data $[8,9,17]$.

Regarding overall complication rates, the American College of Surgeons National Surgery Quality Improvement Program (NSQIP) reported that at 30 days postTHA and TKA, 4.2 and $5.55 \%$ of people experience a major complication i.e. a complication requiring complex medical intervention, and minor complications occurred in 2.17 and $2.86 \%$, respectively $[6,18]$. In Australia, the Bureau of Health Information published readmission rates of 9 and $12 \%$ within 60 days of THA and TKA [19]. However, there are currently no published reports that capture the rates of complications following TKA or THA across multiple providers and include both the acute hospital stay along with postdischarge follow-up to 6 months post-surgery. Capturing and understanding complete rates of minor and major complications help to highlight potential failings in quality of care.

The aims of this study were to use data from an arthroplasty registry to describe complete complication rates from the acute period to six months following
THA and TKA in an Australian context and to describe reasons for reoperation and readmission six months post-surgery. An additional aim was to identify risk factors for complications such as readmission and reoperation, following THA and TKA.

\section{Methods \\ Study design and population}

This retrospective cohort study included elective primary total hip and total knee arthroplasties recorded in the Arthroplasty Clinical Outcomes Registry National (ACORN) with complete follow-up to 6-months postsurgery. ACORN captured complications and patientreported outcome measures for all elective THA and TKA surgeries in ten participating institutions in Australia from September 2012 to September 2018, with follow-up to April 2019. All adults undergoing elective primary or revision THA or TKA at one of ten participating sites and with the cognitive capacity to respond to patient-reported outcome questions were eligible for inclusion in the registry. In this study, patients were excluded if they had undergone revision surgery or unicompartmental knee arthroplasty, opted out of registry follow-up or were lost to follow up. Ethical approval for this study was granted by the Hunter New England $\mathrm{Hu}-$ man Research Ethics Committee (HREC; reference no. 12/11/21/5.02). The HREC also approved the opt-out consent process, meaning that all eligible people were included in the ACORN Registry unless they specifically contacted the registry to opt out.

\section{Data collection in ACORN}

Pre-operatively, ACORN participants provide demographic and anthropometric information and medical history, and complete patient-reported index joint (Oxford Knee or Hip Score [20]) and generic health-related quality of life (EuroQol 5 L-5D [21]) questionnaires. ACORN hospitals collect information about the acute stay on an ACORN proforma including complications, length of stay and discharge destination (e.g. usual residence, inpatient rehabilitation, nursing home, death). Dedicated registry staff collect six-month Oxford Knee or Hip Score and EuroQol 5 L-5D by telephone, as well as information on complications including readmission and reoperation. ACORN Registry staff entered baseline, acute-care and follow-up data into the REDCap database hosted at the University of New South Wales, Australia. ACORN data have high levels of completeness (>99\%) and accuracy (94-96\%) [22].

\section{Outcomes}

Complications were collected at two time points: during the acute inpatient stay, and at six months postoperatively. Complications captured at both time points 
were combined to identify people who had 'ever' or 'never' experienced the complication. We categorised complications into 'major', defined as those requiring complex medical intervention, and 'minor' (all other complications).

Major complications captured at both time points included death, reoperation, dislocation, fracture, deep vein thrombosis (DVT), pulmonary embolism (PE), surgical site infections (SSI) requiring oral antibiotics, SSI requiring intravenous antibiotics, cardiovascular complications and stroke. Arthroplasty-related readmission was captured at 6-month follow-up for which possible responses were DVT, PE, manipulation under anaesthetic, dislocation, SSI, wound dehiscence, index joint revision and other.

Minor complications captured at both time points include bladder infection or urinary retention, respiratory infection, cellulitis, joint stiffness and neuropathy. Delirium, wound dehiscence, fall during stay and hypotension were captured only during the acute admission whilst joint stiffness, unexpected pain, leg length discrepancy, swelling and persistent paraesthesia were captured only at 6 months.

\section{Statistical analysis}

After testing for distributional assumptions, we presented patient characteristics by joint or by complication status using means or medians as appropriate for continuous variables, and number and percent for categorical variables. We estimated the association between preoperative patient factors and outcomes using unconditional logistic regression models. All models were adjusted for age, sex, body mass index (BMI), heart disease, hypertension, diabetes, gastric, lung, renal and neurological disease, anxiety/depression, low back pain, lower limb arthritis other than operated joint, and prior hip or knee arthroplasty [23]. All analyses were conducted using Stata/SE Version 15.1.

\section{Results}

\section{Characteristics of the study cohort}

Of 9458 procedures captured in ACORN between September 2012 and September 2018, 8444 procedures met the inclusion criteria for this study (2782 THA and 5662 TKA). A total of 1014 procedures were excluded due to: revision surgery $(n=312)$; unicompartmental knee arthroplasty $(n=37)$; procedure data missing $(n=2)$;

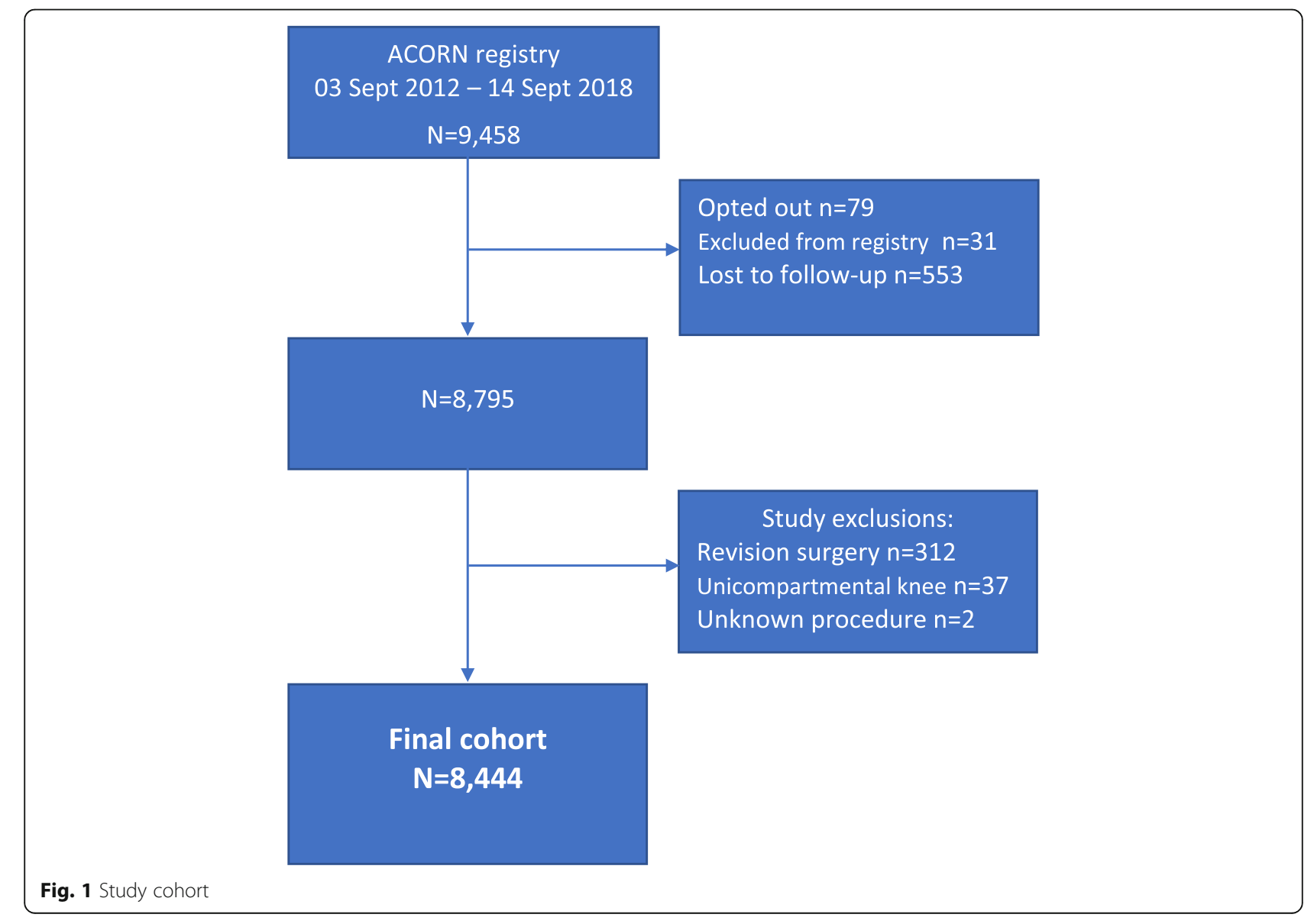


Table 1 Characteristics of the study cohort by joint

\begin{tabular}{|c|c|c|}
\hline & $\begin{array}{l}\text { Hip } \\
N=2782\end{array}$ & $\begin{array}{l}\text { Knee } \\
N=5662\end{array}$ \\
\hline \multicolumn{3}{|l|}{ Demographics } \\
\hline Age, mean (SD) & $67.1(11.5)$ & $68.7(9)$ \\
\hline Male & $1262(45.4)$ & $2157(38.1)$ \\
\hline \multicolumn{3}{|l|}{ Comorbidities } \\
\hline $\mathrm{BMI}$, mean (SD) & $30.4(6.2)$ & $33.2(6.7)$ \\
\hline Heart disease & $923(33.2)$ & $2170(38.3)$ \\
\hline Hypertension & $1425(51.2)$ & $3435(60.7)$ \\
\hline Diabetes & $439(15.8)$ & $1292(22.8)$ \\
\hline Stomach & $488(17.5)$ & $1230(21.7)$ \\
\hline Lung & $416(15)$ & $914(16.1)$ \\
\hline Kidney & $153(5.5)$ & $315(5.6)$ \\
\hline Liver & $58(2.1)$ & $135(2.4)$ \\
\hline Neurological & $147(5.3)$ & $274(4.8)$ \\
\hline Anxiety/depression & $497(17.9)$ & $1006(17.8)$ \\
\hline Low back pain & $1129(40.6)$ & $1861(32.9)$ \\
\hline Other lower limb arthritis & $864(31.1)$ & $1672(29.5)$ \\
\hline \multicolumn{3}{|l|}{ Prior joint replacement } \\
\hline Previous knee arthroplasty & $296(10.6)$ & $1272(22.5)$ \\
\hline Previous hip arthroplasty & $547(19.7)$ & $315(5.6)$ \\
\hline \multicolumn{3}{|l|}{ Patient-reported outcomes } \\
\hline EQ-VAS (Baseline), mean (SD) & $61.5(22.9)$ & $65.9(20.9)$ \\
\hline EQ-VAS (6 months), mean (SD) & $77.5(17.8)$ & $76.1(17.4)$ \\
\hline OHS or OKS (Baseline), mean (SD) & $15.8(8.2)$ & $18.6(8.2)$ \\
\hline OHS or OKS (6 months), mean (SD) & $42.6(7.2)$ & $38.4(8)$ \\
\hline
\end{tabular}

Abbreviations: SD standard deviation, EQ-VAS EuroQoL Visual Analog Scale, minimum score 0 (worst) maximum 100 (best), OHS Oxford Hip Score, minimum score 0 (worst), maximum 48 (best); OKS Oxford Knee Score, minimum score 0 (worst), maximum 48 (best)

patient opted out $(n=79)$; patient did not meet inclusion criteria for the registry i.e. lack of cognitive capacity to respond to patient-reported outcomes $(n=31)$; and loss to follow-up ( $n=553)$ (Fig. 1).

The overall mean age for THA patients was 67 years (SD 11.5) and 69 (SD 9.0) for TKA patients. Fifty-five percent of the THA cohort were female, compared with $62 \%$ of the TKA cohort. The knee cohort had a greater comorbid burden compared to the hip cohort including higher BMI (knee: mean 33.2 [SD 6.7] vs hip: mean 30.4 [SD 6.2]). Patient characteristics are summarised in Table 1.

\section{Complications}

Following THA, 39.7\% of patients had experienced at least one major $(9.5 \%)$ or minor (34.0\%) complication by six months (Table 2). The most reported minor complications included stiffness (8.8\%) and unexpected pain (5.5\%), whereas the most common major complications
Table 2 Proportion of procedures with a complication by timing and severity of complication

\begin{tabular}{lll}
\hline & Hip & Knee \\
& $N=2782$ & $N=5662$ \\
\hline $\begin{array}{ll}\text { During acute admission } \\
\text { Major }\end{array}$ & & $173(3.1)$ \\
Minor & $80(2.9)$ & $540(9.5)$ \\
Overall & $246(8.8)$ & $679(12)$ \\
From discharge to 6 months & \\
Major & $311(11.2)$ & $666(11.8)$ \\
Minor & $192(6.9)$ & $2332(41.2)$ \\
Overall & $775(27.9)$ & $2675(47.2)$ \\
Total & $899(32.3)$ & $815(14.4)$ \\
Major & & $2637(46.6)$ \\
Minor & $263(9.5)$ & $3033(53.6)$ \\
Overall & $947(34.0)$ & \\
\hline
\end{tabular}

were arthroplasty-related readmission (3.9\%), and reoperation $(2.0 \%)$ (Table 3). The most common reasons for readmission were SSI (1.5\%), dislocation $(0.5 \%)$ and pulmonary embolism $(0.2 \%)$, while the most common reasons for reoperation were SSI $(0.7 \%)$, SSI requiring prosthesis removal (0.4\%) and dislocation (0.3\%) (Table 4 ). The mortality rate was $0.2 \%$.

Following TKA, $53.6 \%$ of people experienced at least one complication (major: 14.4\%; minor, 46.6\%; Table 2). The most common minor complications were joint stiffness (18.5\%), swelling (15.6\%) and paraesthesia (15.6\%), while the most common major complications were arthroplastyrelated readmission $(6.0 \%)$ and reoperation (2.5\%; Table 3). The most common reasons for arthroplasty-related readmission following TKA were SSI (2.1\%), manipulation under anaesthesia (MUA) (1.9\%) and DVT (0.4\%), while the most common reasons for reoperation following TKA were joint stiffness (1.5\%) and SSI requiring surgery (0.5\%) (Table 4 ). The mortality rate was $0.2 \%$.

Relative to THA patients, TKA patients reported higher rates of both major (knee: $14.4 \%$ vs hip: $9.5 \%$ ) and minor (knee: $46.6 \%$ vs hip: $34.0 \%$ ) complications, including higher rates of reoperation, readmission, DVT, SSI requiring oral antibiotics, nerve injury, stiffness, unexpected pain, swelling and paraesthesia, whilst THA patients experienced higher rates of dislocation, fracture, leg length discrepancy and bladder infection (Table 3).

\section{Associations between patient factors and complications}

Among THA recipients, comparing people who experienced complications to those who did not, each $1 \mathrm{~kg} / \mathrm{m}^{2}$ increase in BMI, measured at baseline, was associated with increased odds of reoperation (adjusted odds ratio [aOR]: 1.05; 95\% CI: 1.01-1.09), arthroplasty-related readmission (aOR: 1.04; 95\% CI: 1.01-1.07) and SSI (aOR: 
Table 3 Complications by severity and type (includes complications during acute admission and follow-up to 6 months post-surgery)

\begin{tabular}{|c|c|c|}
\hline & $\begin{array}{l}\text { Hip } \\
N=2782\end{array}$ & $\begin{array}{l}\text { Knee } \\
N=5662\end{array}$ \\
\hline Major & $263(9.5)$ & $815(14.4)$ \\
\hline Mortality & $5(0.2)$ & $14(0.2)$ \\
\hline Reoperation & $55(2.0)$ & $144(2.5)$ \\
\hline Arthroplasty-related readmission & $109(3.9)$ & $342(6.0)$ \\
\hline Dislocation & $11(0.4)$ & $4(0.1)$ \\
\hline Fracture & $31(1.1)$ & $21(0.4)$ \\
\hline DVT & $21(0.8)$ & $102(1.8)$ \\
\hline PE & $10(0.4)$ & $33(0.6)$ \\
\hline \multicolumn{3}{|l|}{ Surgical site infection requiring: } \\
\hline Oral antibiotics & $45(1.6)$ & $237(4.2)$ \\
\hline IV antibiotics & $6(0.2)$ & $13(0.2)$ \\
\hline Cardiovascular & $45(1.6)$ & $107(1.9)$ \\
\hline Stroke & $1(0)$ & $1(0)$ \\
\hline Minor & $947(34.0)$ & $2637(46.6)$ \\
\hline Bladder infection or retention & $78(2.8)$ & $133(2.3)$ \\
\hline Respiratory infection & $29(1)$ & $42(0.7)$ \\
\hline Cellulitis & $13(0.5)$ & $50(0.9)$ \\
\hline Nerve injury/ neuropathy & $23(0.8)$ & $71(1.3)$ \\
\hline Delirium $^{a}$ & $24(0.9)$ & $51(0.9)$ \\
\hline Wound dehiscence $^{a}$ & $9(0.3)$ & $34(0.6)$ \\
\hline Pressure area $^{a}$ & $1(0)$ & $3(0.1)$ \\
\hline Fall during hospital stay ${ }^{a}$ & $3(0.1)$ & $23(0.4)$ \\
\hline Hypotension $^{\mathrm{a}}$ & $48(1.7)$ & $43(0.8)$ \\
\hline Drug reaction ${ }^{a}$ & 0 & $2(0)$ \\
\hline Fat embolus $^{\mathrm{a}}$ & 0 & $1(0)$ \\
\hline Other ${ }^{a}$ & $97(3.5)$ & $238(4.2)$ \\
\hline Joint stiffness ${ }^{b}$ & $244(8.8)$ & $1045(18.5)$ \\
\hline Unexpected pain ${ }^{b}$ & $153(5.5)$ & $555(9.8)$ \\
\hline Leg length discrepancy ${ }^{b}$ & $197(7.1)$ & $84(1.5)$ \\
\hline Swelling ${ }^{b}$ & $129(4.6)$ & $881(15.6)$ \\
\hline Paraesthesia $^{\mathrm{b}}$ & $149(5.4)$ & 885 (15.6) \\
\hline Muscle weakness ${ }^{b}$ & $64(2.3)$ & $123(2.2)$ \\
\hline Total (major and minor) & $1103(39.7)$ & $3033(53.6)$ \\
\hline
\end{tabular}

1.07; 95\% CI: 1.02-1.11) at six months. Having undergone a previous THA was associated with increased odds of reoperation (aOR: 2.35; 95\% CI: 1.31-4.23) and arthroplastyrelated readmission (aOR: 2.05; 95\% CI: 1.35-3.14), whilst bilateral surgery was associated with higher odds of SSI (aOR: 4.81; 95\% CI:1.36-17.0) (Table 5).

For TKA patients, age was inversely associated with reoperation (aOR: 0.96 ; 95\% CI: 0.94 to 0.98 ) and surgical
Table 4 Reason for reoperation (post-discharge only) and readmission by joint

\begin{tabular}{lll}
\hline & Hip & Knee \\
& $N=2782$ & $N=5662$ \\
\hline Reoperation & $51(1.8 \%)$ & $138(2.4 \%)$ \\
SSI requiring surgery & $19(0.7)$ & $30(0.5)$ \\
SSI requiring surgery, with prosthesis removal & $10(0.4)$ & $8(0.1)$ \\
Dislocation & $8(0.3)$ & 0 \\
Joint stiffness & 0 & $83(1.5)$ \\
Peri-prosthetic fracture & $4(0.1)$ & $2(0.04)$ \\
Implant fracture & $1(0.04)$ & $1(0.02)$ \\
Bleeding & $2(0.1)$ & 0 \\
Other/unknown & $5(0.2)$ & $14(0.2)$ \\
Readmission (arthroplasty-related) & $109(3.9 \%)$ & $342(6.0 \%)$ \\
DVT & $4(0.1)$ & $23(0.4)$ \\
PE & $5(0.2)$ & $8(0.1)$ \\
Manipulation under anaesthetic & 0 & $106(1.9)$ \\
Dislocation & $14(0.5)$ & 0 \\
SSI & $43(1.5)$ & $117(2.1)$ \\
Wound dehiscence & $1(0.04)$ & $4(0.1)$ \\
Index joint revision & $4(0.1)$ & $1(0.02)$ \\
Other ${ }^{a}$ & $35(1.3)$ & $82(1.4)$ \\
\hline
\end{tabular}

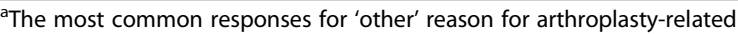
readmission for both joints were 'cellulitis' and 'pain'; 'swelling' was common for knees only

site infection (aOR: 0.98; 95\% CI: 0.97 to 1.00 ), and female sex was inversely associated with arthroplasty-related readmission (aOR: 0.75; 95\% CI: 0.60 to 0.95). Among TKA patients, previous hip arthroplasty was associated with $61 \%$ higher odds of arthroplasty-related readmission (aOR: 1.61; 95\% CI: 1.07 to 2.43) (Table 6). Factors among TKA patients that were associated with an increased odds of minor complications were heart disease (aOR: 1.38; 95\%CI: 1.23-1.55), low back pain (aOR: 1.34; 95\% CI 1.19-1.52) and other lower limb arthritis (aOR: 1.28; 95\% CI 1.13-1.45), whilst previous TKA (aOR: 0.79; 95\% CI: 0.69-0.90) and liver disease (aOR: 0.53; 95\%CI: 0.28-0.99) were associated with a decreased odds of minor complications at 6 months (aOR: 0.79; 95\% CI: 0.69-0.90).

Female sex was associated with increased odds of minor complications following THA (aOR: 1.34; 95\% CI: 1.131.58) but decreased odds following TKA (aOR: 0.85; 95\% CI 0.76-0.95). Results of adjusted regression models outlining associations between patient factors and overall major or minor complications are presented in Table 7.

\section{Discussion}

Summary of main findings

In this analysis of data from an arthroplasty registry in Australia, we found high overall rates of post-operative complications, with $9.5 \%$ of THA and $14.4 \%$ of TKA 
Table 5 Adjusted odds ratios for reoperation, readmission and surgical site infection at 6 months following total HIP arthroplasty

\begin{tabular}{|c|c|c|c|}
\hline & Reoperation & $\begin{array}{l}\text { Readmission } \\
\text { (arthroplasty-related) }\end{array}$ & Surgical site infection \\
\hline Patient factors & $\begin{array}{l}\text { Adjusted OR } \\
(95 \% \mathrm{Cl})\end{array}$ & $\begin{array}{l}\text { Adjusted OR } \\
(95 \% \mathrm{Cl})\end{array}$ & $\begin{array}{l}\text { Adjusted OR } \\
(95 \% \mathrm{Cl})\end{array}$ \\
\hline \multicolumn{4}{|l|}{ Demographics } \\
\hline Age, mean (SD) & $0.98(0.96-1.01)$ & $1.00(0.98-1.02)$ & $0.99(0.96-1.02)$ \\
\hline Female & $1.19(0.67-2.13)$ & $0.96(0.64-1.43)$ & $1.53(0.81-2.88)$ \\
\hline \multicolumn{4}{|l|}{ Comorbidities } \\
\hline $\mathrm{BMI}\left(\mathrm{kg} / \mathrm{m}^{2}\right)$ & $1.05(1.01-1.09)$ & $1.04(1.01-1.07)$ & $1.07(1.02-1.11)$ \\
\hline Heart disease & $1.48(0.81-2.71)$ & $1.42(0.93-2.18)$ & $1.33(0.68-2.60)$ \\
\hline Hypertension & $1.57(0.84-2.94)$ & $1.38(0.89-2.15)$ & $0.65(0.34-1.25)$ \\
\hline Diabetes & $0.58(0.25-1.35)$ & $0.78(0.45-1.35)$ & $0.84(0.36-1.99)$ \\
\hline Stomach & $1.02(0.51-2.06)$ & $0.93(0.55-1.56)$ & $0.51(0.20-1.34)$ \\
\hline Lung & $1.36(0.68-2.69)$ & $1.26(0.76-2.09)$ & $1.97(0.98-3.94)$ \\
\hline Kidney & $0.64(0.15-2.70)$ & $1.01(0.45-2.26)$ & $0.44(0.06-3.29)$ \\
\hline Liver & $1.36(0.30-6.18)$ & $0.80(0.19-3.48)$ & 1 \\
\hline Neurological & $1.18(0.41-3.42)$ & $0.73(0.29-1.84)$ & $1.14(0.34-3.84)$ \\
\hline Anxiety/depression & $1.36(0.70-2.64)$ & $1.06(0.63-1.78)$ & $0.99(0.46-2.15)$ \\
\hline Low back pain & $1.58(0.86-2.88)$ & $1.51(0.99-2.31)$ & $1.39(0.73-2.64)$ \\
\hline Other lower limb arthritis & $0.88(0.47-1.65)$ & $0.97(0.62-11.51)$ & $0.74(0.37-1.49)$ \\
\hline \multicolumn{4}{|l|}{ Prior joint replacement } \\
\hline Previous knee arthroplasty & $0.56(0.19-1.61)$ & $1.12(0.62-2.02)$ & $1.94(0.88-4.31)$ \\
\hline Previous hip arthroplasty & $2.35(1.31-4.23)$ & $2.05(1.35-3.14)$ & $1.38(0.68-2.80)$ \\
\hline \multicolumn{4}{|l|}{ Surgical factors } \\
\hline Bilateral surgery & $1.60(0.21-12.26)$ & $0.81(0.11-6.03)$ & $4.81(1.36-17.0)$ \\
\hline
\end{tabular}

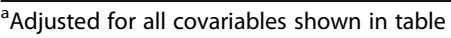

patients having experienced a major complication by 6 months post-surgery; $34.0 \%$ of THA and $46.6 \%$ of TKA patients experienced a minor complication over the same time frame.

\section{Comparison with previous studies Major complications}

Complication rates in our registry were higher than those reported by NSQIP, which reported major and minor 30day complication rates at 4.2 and $2.17 \%$ for THA and 1.83 and $3.20 \%$ for TKA, respectively $[6,18]$. However, our registry follows patients to 6 months rather than 30 days; this longer follow-up period may account for at least part of the difference in complication rates. Our time period was chosen to allow adequate time for improvement in function and complications to surface [24].

\section{Infections}

We found higher rates of surgical site infections to those in the literature. In our TKA cohort, for example, $4.2 \%$ and 0.2 of patients reported SSI requiring oral or IV antibiotics, respectively. A Hong Kong study analysing elective unilateral TKA by a single surgeon over 10 years observed rates of SSI requiring oral antibiotics at $0.66 \%$, whilst a slightly larger Taiwanese study reported a rate of $1.52 \%$ [25, 26]. A large UK prospective study showed superficial SSI at $2.23 \%$ for THA patients compared to our rates of 1.6 and $0.5 \%$ requiring oral and IV antibiotics, respectively [27]. Surgical site infections are important as they can lead to prosthetic joint infections (PJI) which require revision surgery [28]. Rates of PJI requiring revision surgery have been observed in large international studies including the US, Europe, Australia and New Zealand at $0.6-1.6 \%$ for THA and $0.7-1.5 \%$ for TKA $[12,29-33]$ which is higher than the rates found in this study $(\mathrm{THA}=0.4 \%$, TKA $=0.1 \%$ ). However, this is unsurprising as most studies investigating PJI observed a period of 12 - to 24-months post-operatively compared to the 6-month period in this study. Our high rates of oral antibiotic use may reflect low prescribing thresholds rather than an underlying difference in superficial infections.

VTE

We found DVT rates of 0.8 and $1.8 \%$ for THA and TKA. These are higher than reported in previous studies 
Table 6 Adjusted odds ratios for reoperation, readmission and surgical site infection at 6 months following total KNEE arthroplasty

\begin{tabular}{|c|c|c|c|}
\hline & Reoperation & $\begin{array}{l}\text { Readmission } \\
\text { (arthroplasty-related) }\end{array}$ & Surgical site infection \\
\hline Patient factors & $\begin{array}{l}\text { Adjusted OR } \mathrm{OR}^{\mathrm{a}} \\
(95 \% \mathrm{Cl})\end{array}$ & $\begin{array}{l}\text { Adjusted } \mathrm{OR}^{\mathrm{a}} \\
(95 \% \mathrm{Cl})\end{array}$ & $\begin{array}{l}\text { Adjusted OR } \mathrm{OR}^{\mathrm{a}} \\
(95 \% \mathrm{Cl})\end{array}$ \\
\hline \multicolumn{4}{|l|}{ Demographics } \\
\hline Age, mean (SD) & $0.96(0.94-0.98)$ & $0.99(0.98-1.01)$ & $0.98(0.97-1.00)$ \\
\hline Female & $0.76(0.53-1.07)$ & $0.75(0.60-0.95)$ & $1.27(0.96-1.69)$ \\
\hline \multicolumn{4}{|l|}{ Comorbidities } \\
\hline $\mathrm{BMI}\left(\mathrm{kg} / \mathrm{m}^{2}\right)$ & $0.98(0.95-1.01)$ & $1.01(0.99-1.03)$ & $1.01(0.99-1.03)$ \\
\hline Heart disease & $0.91(0.62-1.32)$ & $0.94(0.74-1.20)$ & $0.88(0.67-1.17)$ \\
\hline Hypertension & $0.75(0.52-1.07)$ & $0.80(0.63-1.02)$ & $1.03(0.78-1.37)$ \\
\hline Diabetes & $0.96(0.62-1.49)$ & $0.92(0.70-1.23)$ & $1.02(0.75-1.39)$ \\
\hline Stomach & $0.85(0.54-1.33)$ & $0.97(0.73-1.28)$ & $1.21(0.90-1.64)$ \\
\hline Lung & $0.87(0.53-1.44)$ & $0.95(0.70-1.30)$ & $1.43(1.04-1.96)$ \\
\hline Kidney & $1.84(0.99-3.41)$ & $1.12(0.70-1.79)$ & $0.87(0.48-1.59)$ \\
\hline Liver & $0.98(0.35-2.72)$ & $1.56(0.86-2.82)$ & $0.88(0.38-2.03)$ \\
\hline Neurological & $1.80(0.95-3.42)$ & $1.43(0.91-2.26)$ & $0.93(0.51-1.69)$ \\
\hline Anxiety/depression & $0.92(0.58-1.46)$ & $1.07(0.80-1.43)$ & $1.15(0.83-1.59)$ \\
\hline Low back pain & $1.19(0.82-1.74)$ & $1.22(0.96-1.56)$ & $1.28(0.96-1.70)$ \\
\hline Other lower limb arthritis & $1.33(0.92-1.93)$ & $1.22(0.95-1.56)$ & $0.78(0.58-1.06)$ \\
\hline \multicolumn{4}{|l|}{ Prior joint replacement } \\
\hline Previous knee arthroplasty & $0.73(0.45-1.16)$ & $0.84(0.63-1.12)$ & $0.88(0.64-1.21)$ \\
\hline Previous hip arthroplasty & $1.27(0.63-2.54)$ & $1.61(1.07-2.43)$ & $0.64(0.32-1.26)$ \\
\hline \multicolumn{4}{|l|}{ Surgical factors } \\
\hline Bilateral surgery & $0.61(0.28-1.32)$ & $0.74(0.45-1.21)$ & $0.51(0.26-1.01)$ \\
\hline
\end{tabular}

${ }^{a}$ Adjusted for all covariables shown in table

using inpatient data in the US $(0.24$ and $0.45 \%$ for THA and TKA, respectively) and China $(0.24 \%$ vs $0.71 \%)$, but lower than 90 -days post-operatively in Korea $(2.4 \%$ vs $3.4 \%) \%$ ) $[15,34,35]$, whilst a meta-analysis of patients receiving chemoprophylaxis following THA and TKA published rates of VTE at $1 \%$ for TKA and $0.5 \%$ for THA, again limited to the inpatient stay [16]. The variability seen in these rates may be due to both patient factors including comorbidities and cultural factors, and clinical factors, as such as mechanical and chemoprophylaxis. Previous studies have found higher rates of DVT in patients undergoing TKA compared to THA, and this was reflected in our study with higher rates of both PE and DVT in TKA patients compared to THA. This may be explained by the involvement of smaller calf veins that are affected in TKA compared to larger veins in THA which would take longer to become occluded and therefore symptomatic [16]. Tourniquet use may also contribute to the higher rate of DVT in TKA [36].

\section{Mortality and readmission}

At 6 months, all-cause mortality rates were $0.2 \%$ for both procedures, which falls within the range of published 30- and 90-day rates of $0.05-1.1 \%$ in the US, UK, Australia and Denmark [37-42]. Compared to readmission rates from US Medicare data, we found lower readmission rates at 6 months than the 30-day rates for THA and 90day rates for TKA $[8,9,43]$. We found that infection was overall the most common reason for arthroplastyrelated readmission in both procedures, followed by periprosthetic fracture and dislocation for THA and cellulitis for TKA. A single centre study at a US orthopaedic specialty hospital reported significantly lower rates of 0.33 and $0.21 \%$ for THA and TKA, respectively, at 30 days [17]. However, those numbers are limited to patients who re-present to the same hospital, and therefore those who present to different centres may not have been captured using this metric. Our data is advantageous in this regard as data are collected directly from patients and do not rely on re-presentation to the same institution.

\section{Minor complications overall}

We found significantly higher rates of minor complications in this study at $34.0 \%$ for THA and $46.6 \%$ for TKA compared to published rates of $2.7 \%$ for THA and $3.2 \%$ 
Table 7 Adjusted odds ratios for major and minor complications to 6 months, by joint

\begin{tabular}{|c|c|c|c|c|}
\hline \multirow[b]{3}{*}{ Patient factors } & \multicolumn{2}{|l|}{ Major } & \multicolumn{2}{|l|}{ Minor } \\
\hline & Hip & Knee & Hip & Knee \\
\hline & $\begin{array}{l}\text { Adjusted } \mathrm{OR}^{\mathrm{a}} \\
(95 \% \mathrm{Cl})\end{array}$ & $\begin{array}{l}\text { Adjusted } \mathrm{OR}^{\mathrm{a}} \\
(95 \% \mathrm{Cl})\end{array}$ & $\begin{array}{l}\text { Adjusted } \mathrm{OR}^{\mathrm{a}} \\
(95 \% \mathrm{Cl})\end{array}$ & $\begin{array}{l}\text { Adjusted } \mathrm{OR}^{\mathrm{a}} \\
(95 \% \mathrm{Cl})\end{array}$ \\
\hline \multicolumn{5}{|l|}{ Demographics } \\
\hline Age, mean (SD) & $1.01(0.99-1.02)$ & $1.00(0.99-1.01)$ & $1.00(0.99-1.01)$ & $0.99(0.98-1.00)$ \\
\hline Female & $1.23(0.94-1.61)$ & $0.93(0.79-1.09)$ & $1.34(1.13-1.58)$ & $0.85(0.76-0.95)$ \\
\hline \multicolumn{5}{|l|}{ Comorbidities } \\
\hline BMI $\left(\mathrm{kg} / \mathrm{m}^{2}\right)$ & $1.03(1.01-1.05)$ & $1.01(1.00-1.02)$ & $1.00(0.99-1.01)$ & $1.00(0.99-1.06)$ \\
\hline Heart disease & $1.21(0.90-1.61)$ & $0.95(0.81-1.12)$ & $1.17(0.98-1.41)$ & $1.38(1.23-1.55)$ \\
\hline Hypertension & $0.98(0.74-1.30)$ & $0.93(0.79-1.09)$ & $0.95(0.80-1.14)$ & $0.94(0.84-1.06)$ \\
\hline Diabetes & $1.10(0.78-1.56)$ & $1.04(0.86-1.25)$ & $1.16(0.92-1.45)$ & $0.93(0.81-1.06)$ \\
\hline Stomach & $0.74(0.51-1.07)$ & $1.11(0.92-1.33)$ & $0.96(0.77-1.19)$ & $1.01(0.88-1.15)$ \\
\hline Lung & $1.32(0.94-1.85)$ & $1.20(0.98-1.46)$ & $1.23(0.98-1.53)$ & $1.08(0.94-1.26)$ \\
\hline Kidney & $1.03(0.60-1.79)$ & $1.12(0.82-1.53)$ & $1.07(0.75-1.52)$ & $1.08(0.86-1.39)$ \\
\hline Liver & $0.90(0.34-2.33)$ & $1.07(0.67-1.71)$ & $0.53(0.28-0.99)$ & $0.98(0.69-1.39)$ \\
\hline Neurological & $0.93(0.52-1.66)$ & $1.13(0.80-1.58)$ & $1.14(0.80-1.62)$ & $1.28(1.00-1.64)$ \\
\hline Anxiety/depression & $1.05(0.74-1.48)$ & $1.06(0.87-1.29)$ & $1.09(0.88-1.35)$ & $1.13(0.98-1.31)$ \\
\hline Low back pain & $1.36(1.02-1.80)$ & $1.34(1.14-1.59)$ & $1.16(0.97-1.38)$ & $1.34(1.19-1.52)$ \\
\hline Other lower limb arthritis & $0.80(0.59-1.08)$ & $1.02(0.86-1.21)$ & $1.29(1.08-1.55)$ & $1.28(1.13-1.45)$ \\
\hline \multicolumn{5}{|l|}{ Prior joint replacement } \\
\hline Previous knee arthroplasty & $1.14(0.77-1.70)$ & $0.83(0.69-1.00)$ & $1.23(0.95-1.60)$ & $0.79(0.69-0.90)$ \\
\hline Previous hip arthroplasty & $1.29(0.95-1.75)$ & $1.18(0.87-1.62)$ & $0.98(0.80-1.20)$ & $0.84(0.66-1.06)$ \\
\hline \multicolumn{5}{|l|}{ Surgical factors } \\
\hline Bilateral surgery & $0.84(0.25-2.77)$ & $0.72(0.51-1.02)$ & $1.69(0.90-3.16)$ & $1.15(0.92-1.44)$ \\
\hline
\end{tabular}

for TKA from NSQIP data [6, 18]. The NSQIP data use hospital medical charts documented by medical staff to capture complications, whereas our registry used a combination of hospital data for the acute stay along with patient-reports collected by telephone interview at 6 months. In addition to ACORN registering a larger range of patient-reported minor complications, including hypotension, swelling and paraesthesia, it is possible that patients and surgeons have different conceptions of what constitutes a complication. For example, stiffness may indicate patients' subjective experience, whilst rates of MUA may suggest an objective measurement by surgeons that indicates stiffness severe enough to require intervention. Disagreement in complication reporting rates between clinicians and patients has already been established following orthopaedic and general surgery [44-48]. Although minor complications such as stiffness, swelling and paraesthesia do not necessarily indicate procedure failure, they represent legitimate patient experience, and the absence of measurement standards to characterise their severity may impact the accuracy and reliability of complications data. Further, minor complications may reflect quality of care delivery. For example, high rates of pressure sores may reflect a lack of attention to early ambulation, while high rates of hypotension may reflect too high a dose of intraoperative opioid. Even minor complications are costly to the health system and may be important to patients thus are worth preventing.

\section{Patient characteristics associated with complications}

Our study found low back pain to be an independent predictor for major complications following either THA or TKA, and BMI as a risk factor for major complications following THA. BMI, longer operative time and higher American Society of Anaesthesiologist scores have been identified as independent predictors of postoperative complications overall in both THA and TKA patients $[13,49]$. Bleeding disorder and anaemia have further been identified as risk factors for major complications following THA, and low back pain has been shown to influence functional outcomes following arthroplasty procedures $[6,18,50,51]$. Further, in separate risk-adjusted models we found increasing age to be 
associated with reduced odds of reoperation, and female gender to be associated with decreased odds of readmission. These associations may reflect the selection of patient groups who have lower comorbidity load as eligible and appropriate for surgery. Geriatric patients aged over 85 are significantly less likely to receive TKA than their younger counterparts; it may be that among patients who do undergo arthroplasty, increased age reflects the selection process of appropriate surgical candidates rather than being a protective factor, as only patients with limited comorbidities who are likely to experience long term benefits would be considered for total arthroplasty procedures [6]. Increased BMI in THA was the single patient factor that was consistently positively associated with major complications, including infection, reoperation and readmission which is in accordance with previous studies which showed BMI to have strong associations with dislocation, infection and revision [52, 53]. A study using the New Zealand Joint Registry also reported an OR of 3.73 for PJI in patients with BMI $>40$ compared to patients with BMI < 35 [54].

Increased age, female gender and previous knee arthroplasty were associated with decreased odds of experiencing a minor complication for TKA patients. Although male gender has been identified in the literature as an independent predictor for postoperative complications due to higher rates of comorbidities such as diabetes, hypertension and smoking, we found increased odds of minor complications among women undergoing THA [55].

\section{Strengths and limitations}

A strength of this study is that it is a large cohort with high rates of long-term follow up. Further, contacting patients directly means that complications managed in the community or a different healthcare facility would have been captured which is a potential limitation of studies relying on single centre administrative data [16]. Limitations of our study include potential recall bias, accuracy of patient reports and although not necessarily a drawback of this study, we were unable to make fair comparisons with other similar studies due to differences in follow up time and complication definitions. We did not capture the timing of complications that occurred after hospital discharge, so were not able to determine whether they happened shortly after discharge or later in the 6-month follow-up period. Although complications such as bladder infection or retention and respiratory infection may be expected during the acute hospital admission, after discharge, particularly after the first 30 days, they are less likely to be arthroplastyrelated. Depending on timing, it is possible that some of these complications were not related to surgery and thus may overestimate their true incidence in relation to the procedure. ACORN also did not capture care characteristics, for example, type of VTE or infection prophylaxis received, thus we are unable to provide complication outcomes according to care received.

\section{Conclusions}

This is the first study that uses Australian multicentre data to provide an overview of post-operative complication rates following THA and TKA. We found moderate rates of major complications and high rates of minor post-operative complications, and found several patient factors such as female sex and age to be protective for certain complications in TKA patients, whilst increased BMI and bilateral surgery in THA patients were risk factors for complications. Efforts should be focused on further identifying patients with higher risk and optimising pre- and post-operative care to reduce rates of these complications.

\section{Abbreviations \\ TKA: Total Knee Arthroplasty; THA: Total Hip Arthroplasty; NSQIP: National Surgery Quality Improvement Program; ACORN: Arthroplasty Clinical Outcomes Registry National; DVT: Deep vein thrombosis; PE: Pulmonary embolism; SSI: Surgical site infection; BMI: Body Mass Index; MUA: Manipulation under anaesthesia; PJI: Prosthetic joint infection; VTE: Venous thromboembolism}

\section{Acknowledgements}

Authors would like to acknowledge Shirley Cross for coordinating ACORN follow-up, and the ACORN steering committee for their support.

\section{Authors' contributions}

JN conceived of the original study idea, contributed to study design, data collection, interpretation of results, and provided critical review of the manuscript; $॥$ contributed to study design, data collection and interpretation of results, and provided critical review of the manuscript; $\mathrm{AL}$ contributed to study design, performed all data analysis, contributed to interpretation of results, and provided critical review of the manuscript; SH contributed to study design, interpretation of data and drafted the manuscript. All authors reviewed and approved of the final version of the manuscript.

\section{Funding}

Nil to declare.

\section{Availability of data and materials}

The data is available at Research Data Australia at: https://researchdata.edu. au/acorn-arthroplasty-clinical-registry-national/1461683/?refer_q=rows=15/ sort=score\%20desc/class=collection/p=1/q=acorn/

\section{Ethics approval and consent to participate}

An opt-out consent process was approved by the Hunter New England Human Research Ethics Committee (HREC) in New South Wales, Australia, meaning that all eligible people were included in the ACORN Registry unless they specifically contacted the registry to opt out. This consent was informed by an HREC-approved written patient information sheet, given to and discussed with each patient during their pre-operative assessment. Ethical approval for this study was granted by the Hunter new England Human Research Ethics Committee (reference no. 12/11/21/5.02).

Consent for publication

Not applicable.

Competing interests

The authors declare that they have no competing interests. 


\section{Author details}

${ }^{1}$ Hornsby-Kuringai Hospital, Palmerston Road, Hornsby, Sydney, NSW 2077, Australia. ${ }^{2}$ Whitlam Orthopaedic Research Centre, Ingham Institute for Applied Medical Research, South Western Sydney Clinical School, UNSW, Sydney, Australia.

Received: 6 April 2020 Accepted: 26 August 2020

Published online: 10 September 2020

\section{References}

1. Australian Orthopaedic Association National Joint Replacement Registry (AOANJRR). Hip, Knee \& Shoulder Arthroplasty: 2019 Annual Report. Adelaide: $\mathrm{AOA} ; 2019$.

2. Kurtz S, Ong K, Lau E, Mowat F, Halpern M. Projections of primary and revision hip and knee arthroplasty in the United States from 2005 to 2030. J Bone Joint Surg Am. 2007;89(4):780-5.

3. Neuprez A, Neuprez AH, Kaux JF, et al. Total joint replacement improves pain, functional quality of life, and health utilities in patients with late-stage knee and hip osteoarthritis for up to 5 years. Clin Rheumatol. 2019;39(3): 861-71.

4. Neuprez A, Neuprez AH, Kaux JF, et al. Early clinically relevant improvement in quality of life and clinical outcomes 1 year Postsurgery in patients with knee and hip joint Arthroplasties. Cartilage. 2018;9(2):127-39.

5. Lenguerrand E, Wylde V, Gooberman-Hill R, et al. Trajectories of pain and function after primary hip and knee arthroplasty: the adapt cohort study. PLoS One. 2016:11(2):e0149306.

6. Belmont PJ, Goodman GP, Waterman B, Bader J, Schoenfeld A. Thirty-day postoperative complications and mortality following total knee arthroplasty: incidence and risk factors among a national sample of 15.321 patients. J Bone Joint Surg Am. 2014;96(1):20-6.

7. Goodman SM, Mehta B, Mirza SZ, et al. Patients' perspectives of outcomes after total knee and total hip arthroplasty: a nominal group study. BMC Rheumatol. 2020;4(1):1-9.

8. Kurtz SM, Lau EC, Ong KL, Adler EM, Kolisek FR, Manley MT. Hospital, patient, and clinical factors influence 30 - and 90-day readmission after primary Total hip Arthroplasty. J Arthroplast. 2016;31(10):2130-8.

9. Kurtz SM, Lau EC, Ong KL, Adler EM, Kolisek FR, Manley MT. Which hospital and clinical factors drive 30- and 90-day readmission after TKA? J Arthroplast. 2016;31(10):2099-107.

10. Liddle AD, Judge A, Pandit H, Murray DW. Adverse outcomes after total and unicompartmental knee replacement in 101330 matched patients: a study of data from the National Joint Registry for England and Wales. Lancet. 2014;384(9952):1437-45.

11. Courtney PM, Boniello AJ, Berger RA. Complications following outpatient Total joint Arthroplasty: an analysis of a National Database. J Arthroplast. 2017;32(5):1426-30.

12. Partridge $T$, Jameson $S$, Baker $P$, Deehan D, Mason J, Reed MR. Ten-year trends in medical complications following 540, 623 primary total hip replacements from a national database. JBJS. 2018;100(5):360-7.

13. Oviedo Baena AM, Moeschler SM, Smith HM, Duncan CM, Schroeder DR, Kopp SL. Perioperative comorbidities and complications among patients undergoing primary total knee arthroplasty: a retrospective analysis and prospective survey. J Clin Anesth. 2015;27(7):558-65.

14. Bedard NA, Pugely AJ, McHugh MA, Lux NR, Bozic KJ, Callaghan JJ. Big data and Total hip Arthroplasty: how do large databases compare? I Arthroplast. 2018;33(1):41-5

15. Lee S, Hwang Jl, Kim Y, Yoon PW, Ahn J, Yoo JJ. Venous thromboembolism following hip and knee replacement arthroplasty in Korea: a nationwide study based on claims registry. J Korean Med Sci. 2016;31(1):80-8.

16. Crowther MA, Burnand B. CLINICIAN'S CORNER symptomatic in-hospital deep vein thrombosis and pulmonary embolism following hip and knee Arthroplasty among patients. JAMA. 2014;307(3):294-303.

17. Ricciardi BF, Oi KK, Daines SB, Lee YY, Joseph AD, Westrich GH. Patient and perioperative variables affecting 30-day readmission for surgical complications after hip and knee Arthroplasties: a matched cohort study. J Arthroplast. 2017;32(4):1074-9.

18. O'Malley NT, Fleming FJ, Gunzler DD, Messing SP, Kates SL. Factors independently associated with complications and length of stay after hip Arthroplasty. Analysis of the National Surgical Quality Improvement Program. J Arthroplsaty. 2012;27(10):1832-7.
19. Bureau of Health Information. Exploring clinical variation in readmission return to acute care following discharge from hospital, eight clinical conditions, NSW, July 2012 - June 2015. Sydney (NSW): BHI; 2017.

20. Murray DW, Fitzpatrick R, Rogers K, et al. The use of the Oxford hip and knee scores. JBJS. 2007:8:1010-4.

21. Stolk E, Ludwig K, Rand K, van Hout B, Ramos-Goñi JM. Overview, update, and lessons learned from the international EQ-5D-5L valuation work: version 2 of the EQ-5D-5L valuation protocol. Value Health. 2019;22(1):23-30.

22. Seagrave, et al. Data quality audit of the arthroplasty clinical outcomes registry NSW. BMC Health Serv. 2014;14:512.

23. Sun G-W, Shook TL, Kay GL. Inappropriate use of Bivariable analysis to screen risk factors for use in multivariable analysis. J Clin Epidemiol. 1996; 49(8):907-16.

24. Churches T, Naylor J, Harris I. Arthroplasty clinical outcomes registry national (ACORN) annual report 2017. Liverpool: Whitlam Orthopaedic Research Centre; 2018.

25. Teo BJX, Yeo W, Chong HC, Tan AHC. Surgical site infection after primary total knee arthroplasty is associated with a longer duration of surgery. J Orthop Surg (Hong Kong). 2018;26(2):1-7.

26. Wu CT, Chen IL, Wang JW, Ko JY, Wang CJ, Lee CH. Surgical site infection after Total knee Arthroplasty: risk factors in patients with timely Administration of Systemic Prophylactic Antibiotics. J Arthroplast. 2016;31(7): 1568-73.

27. Ridgeway S, Wilson J, Charlet A, Katafos G, Pearson A, Coello R. Infection of the surgical site after arthroplasty of the hip. JBJS. 2005;87(6):844-50.

28. Galat DD, McGovern SC, Larson DR, Harrington JR, Hanssen AD, Clarke HD Surgical treatment of early wound complications following primary total knee arthroplasty. JBJS. 2009;22(2):313.

29. Zhu M, Ravi S, Frampton C, Luey C, Young S. New Zealand joint registry data underestimates the rate of prosthetic joint infection. Acta Orthop. 2016;87(4):346-50

30. Badawy M, Fenstad AM, Bartz-Johannessen CA, et al. Hospital volume and the risk of revision in Oxford unicompartmental knee arthroplasty in the Nordic countries -an observational study of 14,496 cases. BMC Musculoskeletal Disord. 2017;18(1):1-8.

31. Huotari K, Lyytikäinen O, Ollgren J, et al. Disease burden of prosthetic joint infections after hip and knee joint replacement in Finland during 19992004: capture-recapture estimation. J Hosp infect. 2010;75(3):205-8.

32. Phillips JE, Crane TP, Noy M, Elliott TSJ, Grimer RJ. The incidence of deep prosthetic infections in a specialist orthopaedic hospital. A 15-year prospective survey. JBJS. 2006;88(7):943-8.

33. Lindeque B, Hartman Z, Noshchenko A, Cruse M. Infection after primary total hip arthroplasty. Orthopedics. 2014;37(4):257-65.

34. Dua A, Desai SS, Lee CJ, Heller JA. National Trends in deep vein thrombosis following Total knee and Total hip replacement in the United States. Ann Vasc Surg. 2017;38:310-4.

35. Xu H, Zhang $\mathrm{S}$, Xie J, et al. A nested case-control study on the risk factors of deep vein thrombosis for Chinese after total joint arthroplasty. J Orthop Surg Res. 2019;14(1):1-7.

36. Tai TW, Lin CJ, Jou IM, Chang CW, Lai KA, Yang CY. Tourniquet use in total knee arthroplasty: a meta-analysis. Knee Surg Sports Traumatol Arthrosc. 2011;19(7):1121-30.

37. Smith EJ, Maru M, Siegmeth A. Thirty-day mortality after elective hip and knee arthroplasty. Surgeon. 2015;13(1):5-8.

38. Belmont PJ, Goodman GP, Hamilton W, Waterman BR, Bader JO, Schoenfeld AJ. Morbidity and mortality in the thirty-day period following total hip arthroplasty: risk factors and incidence. J Arthroplast. 2014;29(10):2025-30.

39. Berstock JR, Beswick AD, López-López JA, Whitehouse MR, Blom AW. Mortality after total knee arthroplasty: a systematic review of incidence, temporal trends, and risk factors. JBJS. 2018;100(12):1064-70.

40. Hunt LP, Ben-Shlomo Y, Clark EM, et al. 90-day mortality after 409096 total hip replacements for osteoarthritis, from the National Joint Registry for England and Wales: a retrospective analysis. Lancet. 2013;382(9898):1097-104.

41. Illingworth KD, el Bitar YF, Banerjee D, Scaife SL, Saleh KJ. Inpatient mortality after primary Total hip Arthroplasty: analysis from the National Inpatient Sample Database. J Arthroplast. 2015;30(3):369-73.

42. Harris IA, Hatton A, Steiger R, Lewis P, Graves S. Declining early mortality after hip and knee arthroplasty. ANZ J Surg. 2020;90(1-2):119-22.

43. Saucedo JM, Marecek GS, Wanke TR, Lee J, Stulberg SD, Puri L. Understanding readmission after primary total hip and knee arthroplasty: Who's at risk? J Arthroplast. 2014;29(2):256-60. 
44. Fränneby U, Gunnarsson U, Wollert S, Sandblom G. Discordance between the patient's and surgeon's perception of complications following hernia surgery. Hernia. 2005;9(2):145-9.

45. Veen EJ, Steenbruggen J, Roukema JA. Classifying surgical complications: a critical appraisal. Arch Surg. 2005;140(11):1078-83.

46. Mannion AF, Fekete TF, O'Riordan D, et al. The assessment of complications after spine surgery: time for a paradigm shift? Spine J. 2013;13(6):615-24.

47. Greenbaum JN, Bornstein LJ, Lyman S, Alexiades MM, Westrich GH. The validity of self-report as a technique for measuring short-term complications after Total hip Arthroplasty in a joint replacement registry. J Arthroplast. 2012;27(7):1310-5.

48. Alazzawi S, Bardakos NV, Hadfield SG, Butt U, Beer ZH, Field RE. Patientreported complications after elective joint replacement surgery: are they correct? JBJS. 2012;94(8):1120-5.

49. DeMik DE, Bedard NA, Dowdle SB, et al. Complications and obesity in Arthroplasty—a hip is not a knee. J Arthroplast. 2018;33(10):3281-7.

50. Staibano P, Winemaker M, Petruccelli D, de Beer J. Total joint arthroplasty and preoperative low back pain. J Arthroplast. 2014;29(5):867-71.

51. Boyle JK, Anthony IC, Jones BG, Wheelwright EF, Blyth MJG. Influence of low back pain on total knee arthroplasty outcome. Knee. 2014;21 (2):410-4.

52. Wagner ER, Kamath AF, Fruth KM, Harmsen WS, Berry DJ. Effect of body mass index on complications and reoperations after total hip arthroplasty. J Bone Joint Surg Am. 2016;98(3):169-79.

53. Wagner ER, Kamath AF, Fruth K, Harmsen WS, Berry DJ. Effect of body mass index on reoperation and complications after total knee arthroplasty. J Bone Joint Surg Am. 2016;98(24):2052-60

54. Smith JO, Frampton CMA, Hooper GJ, Young SW. The impact of patient and surgical factors on the rate of postoperative infection after Total hip Arthroplasty - a New Zealand joint registry study. J Arthroplast. 2018;33(6): 1884-90.

55. Basques BA, Bell JA, Sershon RA, della Valle CJ. The influence of patient gender on morbidity following Total hip or Total knee Arthroplasty. J Arthroplast. 2018:33(2):345-9.

\section{Publisher's Note}

Springer Nature remains neutral with regard to jurisdictional claims in published maps and institutional affiliations.

Ready to submit your research? Choose BMC and benefit from:

- fast, convenient online submission

- thorough peer review by experienced researchers in your field

- rapid publication on acceptance

- support for research data, including large and complex data types

- gold Open Access which fosters wider collaboration and increased citations

- maximum visibility for your research: over $100 \mathrm{M}$ website views per year

At $\mathrm{BMC}$, research is always in progress.

Learn more biomedcentral.com/submissions 